\title{
La problématique de l'identité appliquée à la catégorie des chômeurs
}

Identification and identity of the unemployed

Isabelle Raynaud

\section{OpenEdition}

\section{Journals}

Édition électronique

URL : https://journals.openedition.org/rhcf/151

DOI : 10.4000/rhcf.15

\section{Éditeur}

Rails \& histoire

\section{Édition imprimée}

Date de publication : 1 décembre 2007

Pagination : 206-219

ISSN : 0996-9403

Référence électronique

Isabelle Raynaud, «La problématique de l'identité appliquée à la catégorie des chômeurs », Revue d'histoire des chemins de fer [En ligne], 36-37 | 2007, mis en ligne le 10 mai 2011, consulté le 22 avril 2022. URL : http://journals.openedition.org/rhcf/151 ; DOI : https://doi.org/10.4000/rhcf.151 


\title{
La problématique de l'identité appliquée à la catégorie des chômeurs
}

\author{
Isabelle Raynaud \\ Doctorante, université du Havre
}

La construction du chômage en tant que catégorie statistique remonte à un siècle. Alors que le salariat et le contrat de travail sont constitués en norme, l'État invente la notion de chômage pour caractériser le manque de travail involontaire et temporaire ${ }^{1}$. Au cours du XX siècle, le modèle du salariat s'est progressivement imposé, non sans àcoups. Après la Seconde Guerre mondiale, il s'incarne dans un contrat de travail stable ouvrant des droits qui incluent, à partir de 1958, le droit à la protection contre le chômage. Dans une société où le travail occupe une place centrale, le chômage est perçu et vécu sur un mode négatif. Il s'apparente à un vide, à un manque. Les études en sciences humaines et sociales montrent l'importance du travail dans la construction des identités à la fois sociale, professionnelle et collective. En retour, le chômage porte atteinte à l'identité tant individuelle que collective, comme en témoignent diverses études de sociologie.

Si le concept d'identité en lui-même fait débat, nous pouvons cependant le caractériser par quelques attributs principaux, qui peuvent se résumer dans la formule « je, nous et les autres ». L'identité suppose une conscience de soi, le sentiment d'appartenance plus ou moins fort à un groupe dont les membres sont perçus comme des semblables. Ce groupe se différencie dans la société par une culture commune, spécifique, ce qui suppose l'existence d'une altérité. Cette problématique de l'identité occupe aujourd'hui une place centrale dans les sciences sociales. Mais, appliquée à la catégorie des chômeurs, elle est problématique, dans la mesure où l'identité du chômeur constitue en elle-même une aporie. En effet, le chômage, bien que constitué en catégorie, ne débouche pas sur la création d'une identité collective. Il met également en

1- Sur les origines du chômage, on pourra notamment consulter: Nicolas Baverez, Bénédicte Reynaud et Robert Salais, L'Invention du chômage. Histoire et transformations d'une catégorie en France des années 1890 aux années 1980, Paris, PUF, 1986; Malcolm Mansfield, Robert Salais et Noël Whiteside (dir.), Aux sources du chômage. 1880-1914, Paris, Belin, 1994 ; Christian Topalov, Naissance du chômeur, 1880-1910, Paris, Albin Michel, 1994. 
jeu l'identité des individus, malgré la diversité des expériences du chômage. Défini comme une condition sociale négative, le chômage semble réduire les individus au silence. Cependant, les luttes de chômeurs remettent en question cette approche. Malgré son caractère sporadique, l'action collective des chômeurs conduit-elle à l'expression d'une identité collective, a priori improbable?

\section{Pourquoi n'existe-t-il pas une identité collective des chômeurs?}

Le chômage peut-il susciter un sentiment d'appartenance? L'étude sociologique du groupe des chômeurs conduit à répondre par la négative. D'autres facteurs expliquent également cette absence d'identité collective : l'image des chômeurs apparaît ambiguë et multiple. De plus, la représentation politique des chômeurs est improbable.

Une catégorie sociale, mais un groupe hétérogène

Constitué en catégorie sociale, le chômage n'engendre pas pour autant un processus d'identification. Le groupe social des chômeurs est en effet très hétérogène. Le sexe, l'âge, ainsi que la qualification (ou non), la durée du chômage et les ressources dont disposent les chômeurs créent une hétérogénéité du groupe. Il n'existe donc pas un statut social du chômeur. En effet, le chômage n'ouvre pas les mêmes aides et les mêmes droits pour tous; il ne frappe pas non plus tous les chômeurs de la même façon. Or la notion de statut se définit comme un ensemble (plus ou moins systématisé et relativement fixe) de comportements que l'on peut attendre, aussi bien d'un individu placé dans une situation donnée, que de la société à l'égard de cet individu ; ce «code » étant légitimement reconnu par l'individu comme par la société2. Si la création de l'assurance obligatoire contre le chômage en 1958 a permis la création d'un statut du chômeur, ce statut a connu un éclatement, dans le contexte d'un chômage de masse durable depuis le milieu des années 1970. Progressivement, le revenu de remplacement a diminué, la part des chômeurs indemnisés parmi les demandeurs d'emploi a elle aussi baissé. Certains d'entre eux relèvent du système d'assistance et non de l'assurance.

2- Nous nous appuyons ici sur la définition donnée par Olivier Fillieule de la notion de statut, dans son chapitre intitulé " Conscience politique, persuasion et mobilisation des engagements. L'exemple du syndicat des chômeurs, 1983-1989 », in Olivier Fillieule (dir.), Sociologie de la protestation. Les formes de l'action collective dans la France contemporaine, Paris, L'Harmattan, 1993, p. 131. 
C'est ainsi le cas des chômeurs bénéficiaires du revenu minimum d'insertion, par exemple. Le traitement social du chômage conduit à classer les demandeurs d'emploi dans des sous-catégories, voire à faire des chômeurs autant de "problèmes sociaux » irréductibles ${ }^{3}$.

Cependant, l'hétérogénéité du groupe des sans-emploi n'est pas un phénomène récent. Elle est aussi ancienne que la catégorie du chômage. Les premiers secours contre le chômage se mettent en place en France à partir de 1914. Jusque-là, les chômeurs peuvent s'adresser aux bureaux de bienfaisance, au même titre que les pauvres. Les débuts de l'indemnisation dans l'entre-deux-guerres n'ont qu'un effet très limité. Tous les chômeurs sont loin d'être concernés. Les fonds de chômage sont gérés par les municipalités et ne touchent que les régions industrielles et urbaines. Encore les villes ne sont-elles pas contraintes d'indemniser le chômage. Surtout, toutes les professions ne sont pas prises en compte. Le groupe des chômeurs présente alors une forte hétérogénéité, selon que le sans-emploi perçoit une allocation versée par son syndicat, un secours du fonds de chômage, voire en dernier recours une aide du bureau de bienfaisance. Derrière la catégorie officielle il n'existe donc pas un groupe social des chômeurs uni et cohérent.

L'absence de processus d'identification est également liée à la nature même du chômage. Contrairement à la retraite, par exemple, le chômage se caractérise par l'incertitude de sa fin. Il ne constitue donc pas un état, mais une condition, voulue temporaire par les chômeurs. Le chômage est ainsi perçu comme un moment qui crée une rupture dans un itinéraire, une carrière. Il peut être vécu également comme un passage et constituer un temps de mobilité, une transition. Ainsi on ne se revendique pas ou rarement comme chômeur. Il faut d'ailleurs souligner la distinction que nombre de chômeurs font eux-mêmes entre "être chômeur» et "être au chômage »" ${ }^{5}$, cette dernière formulation étant souvent préférée.

\section{Le chômage entre réalité objective et jugement moral}

La catégorie officielle du chômage débouche sur une catégorie juridique qui se caractérise par l'absence de travail et la recherche d'un emploi. Cependant, cette catégorie ne se réduit pas à un fait objectif.

3- Emmanuel Pierru, Guerre aux chômeurs ou guerre au chômage, Broissieux, Éditions du croquant, 2005.

4- Christine Daniel et Carole Tuschzirer, L'État face aux chômeurs. L'indemnisation du chômage de 1884 à nos jours, Paris, Flammarion, 1999.

5- Didier Demazière a notamment souligné ce point : Didier Demazière, Le Chômage. Comment peut-on être chômeur? Paris, Belin, 2003. 
Ainsi, lors des entretiens à l'ANPE, les agents, en effectuant un bilan sur la situation de chaque chômeur, opèrent un jugement fondé sur l'employabilité du chômeur. Celle-ci est notamment fonction de la volonté du demandeur d'emploi et de la possibilité qu'il a de trouver un emploi sur le marché du travail (par exemple, selon son âge).

Il faut cependant s'arrêter sur cette notion d'employabilité, apparue dans les années 1990. Dans le contexte de la mondialisation économique et donc de la compétition accrue entre les entreprises au niveau mondial, les employeurs garantissent de moins en moins l'emploi. C'est au salarié d'assurer sa propre compétitivité sur le marché du travail, en développant ses compétences. Il s'agit donc d'une transformation profonde du contrat de travail, en général expliquée par les décalages entre les compétences des salariés et les besoins des entreprises. Cette transformation s'inscrit dans le courant libéral actuel. Fondé initialement sur une base relationnelle entre l'entreprise et le salarié, le contrat de travail devient de plus en plus transactionnel : l'employé est engagé en vue d'une opération concrète, d'une mission, dont le résultat est attendu et évalué. Cette évolution explique notamment la mise à l'écart, plus ou moins brutale, d'une partie des chômeurs, considérés comme inemployables. Selon cette conception, les demandeurs d'emploi doivent s'adapter pour intégrer le marché du travail. Ainsi le chômage opère comme une catégorie morale, qui se fonde sur un jugement. Cette catégorie peut rapidement devenir oppressante.

Dès les origines du chômage, le souci de distinguer entre « vrais » et «faux » chômeurs s'exprime. Les autorités en charge des fonds de chômage s'inquiètent des risques de fraude. Les secours sont maintenus à un faible niveau et pour une durée limitée, par crainte de décourager le travail. Une certaine suspicion existe à l'égard des « mauvais » ouvriers ou « chômeurs professionnels » qui sont considérés comme indignes de l'assistance contre le chômage. Par ailleurs, jusqu'à la création de l'UNEDIC en 1958, les conditions d'accès à l'indemnisation sont très restrictives et les chômeurs font l'objet d'un contrôle sévère, incluant des enquêtes de moralité et de voisinage ${ }^{6}$. Depuis l'entrée dans un chômage de masse durable à partir de 1974, la préoccupation de distinguer parmi les demandeurs d'emploi ceux qui sont dignes d'intérêt de ceux qui sont jugés responsables de leur situation resurgit sous différentes formes. L'image dominante du chômeur présente donc une véritable

6- C. Daniel et C. Tuschzirer, op. cit.; Isabelle Raynaud, « Les luttes de chômeurs : des révoltes sans lendemain? Histoire des mobilisations de chômeurs en Seine-Maritime des années 1880 à 1998 », mémoire de Master 2, université du Havre, 2005. 
ambivalence. Elle associe deux dimensions : d'un côté celle du chômeur victime et menacé par la déchéance sociale, de l'autre celle du chômeur suspect d'être responsable de sa situation de non-emploi. Encore les deux faces de la médaille ne sont-elles pas si tranchées, ni opposées ; on peut facilement glisser de l'une à l'autre, car le chômage est réputé affaiblir l'individu. Cette représentation rend d'autant plus difficile pour le chômeur l'acceptation de sa condition.

\section{L'improbable représentation politique des chômeurs}

Devant la dégradation du rapport salarial et la précarité à laquelle sont de plus en plus confrontés les chômeurs, le chômage est assimilé à un processus d'exclusion ${ }^{7}$. Les études sur le chômage de longue durée en témoignent ${ }^{8}$. Marginalisé, puis exclu de la norme du salariat, le chômeur devient un sans-travail et un sans-voix. Lorsqu'il a épuisé ses droits, il dépend alors du système d'assistance ou peut bénéficier du soutien d'associations caritatives, du fait de sa situation de pauvreté. Cette dernière engendre un déni de citoyenneté et une forme de relégation.

La politique de lutte contre le chômage est débattue sans les chômeurs. De plus, quand tout le monde s'élève contre le chômage, quel responsable désigner comme adversaire ? Ainsi la représentation politique du chômage et des chômeurs est-elle largement improbable. Les organisations de chômeurs sont absentes des instances de gestion du chômage. Lorsque, en janvier 1998, elles ont été reçues officiellement à Matignon, une mobilisation nationale inédite les avait imposées comme interlocuteur. Cependant, elles n'en ont pas pour autant acquis un statut d'organisations représentatives et donc d'interlocuteur véritable.

Le chômage, bien que partagé et vécu par une masse d'individus, ne crée pas d'identité collective. Il est une condition, plus qu'un statut, de plus en plus associée à la précarité. Le groupe des chômeurs est réputé atomisé, réduit au silence et à l'apathie par l'épreuve individuelle que constitue le chômage.

7- Sur le concept d'exclusion, voir notamment: Serge Paugam (dir.), L'Exclusion. L'état des savoirs, Paris, La Découverte, 1996.

8- Notamment: Didier Demazière, Marc Helleboid et Jacques Mondoloni, Longue durée. Viure en chômage, Paris, Syros, 1994. Également: Didier Demazière, Le Chômage de longue durée, Paris, PUF, 1995. 


\section{Comment le chômage met-il en cause les identités indivi- duelles?}

Si le groupe des chômeurs semble très artificiel et éclaté, comment le chômage est-il vécu par les individus ? Dans quelle mesure l'expérience du chômage remet-elle en cause l'identité individuelle ? La sociologie a largement étudié cette dimension et les travaux permettent de dresser une sorte de typologie des chômeurs.

\section{Le chômage : une dévalorisation de soi}

Dès les premières études sociologiques, une place centrale est faite au processus de désocialisation des chômeurs. L'enquête pionnière de Paul Lazarsfeld auprès des "chômeurs de Marientahl », publiée en 1932, en témoigne?. A l'époque, les chômeurs ne disposent d'aucun droit ni statut dans la société. La protection contre le chômage reste embryonnaire. Ainsi l'enquête menée dans une petite ville ouvrière d'Autriche, touchée par un chômage de masse, est axée sur la perte de statut social engendrée par le chômage. Si les conséquences matérielles du chômage occupent une place importante dans l'analyse, celle-ci s'intéresse surtout à l'évolution des liens sociaux au sein de la communauté étudiée. Le travail vise à décrire les menaces que le chômage fait peser sur la cohésion sociale.

Dans un contexte économique et social très différent, marqué par un chômage de masse durable, largement structurel, le vécu du chômage a fait l'objet de multiples recherches. Dans un ouvrage publié pour la première fois en 1981 et intitulé L'Épreuve du chômage, Dominique Schnapper distingue différentes attitudes face au chômage ${ }^{10}$. Le « chômage total» entraine pour l'individu une perte du statut social acquis par le travail. Il est vécu comme une souffrance et une épreuve ; il peut être ressenti comme une honte, car l'individu se sent dévalorisé. Ce vécu du chômage est très nettement majoritaire. Le sentiment d'inutilité sociale remet l'identité en question. Le chômage peut entraîner une désocialisation et une marginalisation de l'individu. Au-delà de la dévalorisation de soi, le chômage peut conduire, selon certains sociologues, à la constitution d'une identité négative, due au processus de disqualification sociale, notamment lorsqu'il est cumulé à d'autres handicaps ${ }^{11}$.

9- Marie Jahoda, Paul Lazarsfeld et Hans Zeisel, Les Chômeurs de Marienthal, Paris, Éditions de Minuit, 1981.

10- Dominique Schnapper, L'Éprewve du chômage, Paris, Gallimard, 1981, rééd. 1994.

11- Serge Paugam, La Disqualification sociale, Paris, PUF, 2004. 
L'absence de qualification rend le vécu du chômage plus dur. Certains groupes ou individus sont plus vulnérables au chômage. Le chômage de longue durée notamment est un phénomène fortement sélectif et structurel. Les sans-travail ont plus de chance d'être issus des catégories les plus dénuées de pouvoir social ${ }^{12}$.

\section{La diversité des vécus du chômage}

L'expérience du chômage ne peut cependant se résumer à la figure, voire au stéréotype du chômeur abattu, résigné, marginalisé. Si le chômage signifie, pour une majorité de demandeurs d'emploi, une « galère », il n’aboutit pas nécessairement à une déchéance de l'individu.

Dans la typologie dressée par Dominique Schnapper, deux attitudes se distinguent de celle du «chômage total » dominant. Le « chômage différé » est le fait des chômeurs qui conduisent leur recherche d'emploi sur le mode d'une activité à temps plein. La règle de la concurrence sur le marché du travail est acceptée. Le chômage est vécu comme une étape à dépasser par un investissement, aussi intense que s'il s'agissait d'un travail. Dans ce cas, l'individu continue de s'identifier par sa profession. Il met ses ressources au service de son objectif prioritaire : le retour au travail.

Au contraire, dans le " chômage inversé », l'individu fait le choix de consacrer son temps à des activités non salariées, non rémunérées, telles que des activités créatrices, familiales ou encore militantes. Dans ce cas, le travail est perçu comme aliénant et l'individu revendique son émancipation vis-à-vis du travail et son choix de vivre autrement ${ }^{13}$. Ces deux «mondes vécus du chômage » sont, cependant, beaucoup moins fréquents que le «chômage total ». En outre, des variables telles que le sexe, l'âge et l'appartenance sociale établissent une forte différenciation dans le rapport de l'individu au chômage. La typologie dressée par D. Schnapper montre bien que le chômage peut être vécu très différemment selon les ressources de l'individu. Par ressource, il faut entendre

12- Olivier Fillieule, art. cit.

13- Le film Attention Danger travail (2003; réalisation : Pierre Carles, Christophe Coello et Stéphane Goxe) rassemble ainsi une dizaine de témoignages de chômeurs ayant choisi de vivre sans travailler. Le documentaire s'intéresse à la contestation de la valeur travail. Sur ce point, voir également le «Manifeste des chômeurs heureux » élaboré en 1996. Ce courant remet en cause la place du travail et centre sa réflexion autour de la question du revenu, en proposant de déconnecter ce dernier du travail, par la revendication d'un revenu garanti. Sur ce sujet, voir notamment : "Vers un revenu minimum inconditionnel ? ", Revue du MAUSS semestrielle $\mathrm{n}^{\circ}$ 7, $1^{\mathrm{er}}$ semestre 1996. 
non seulement les moyens financiers de la personne, mais également la capacité à adopter des activités de substitution, la socialisation de l'individu, son intégration familiale ${ }^{14}$. Ainsi, que peuvent avoir en commun un ouvrier non qualifié et un cadre frappés par le chômage?

Plus l'attachement et l'identification au travail sont forts, plus le chômage risque de fragiliser l'individu dans sa propre identité. Le titre de l'ouvrage de Danièle Linhart, Perte d'emploi, perte de soi, symbolise précisément cela ${ }^{15}$. L'auteur présente les résultats d'une enquête menée auprès d'ouvriers licenciés suite à la fermeture de l'usine Chausson de Creil en 1996. La centralité du travail dans la construction de l'identité sociale est d'autant plus nette avec l'absence de travail. Ainsi les chômeurs attribuent massivement au travail une valeur centrale ${ }^{16}$.

\section{Arrangements des chômeurs avec l'identité}

Les vécus du chômage diffèrent et les chômeurs sont conduits à négocier leur identité dans une sorte d'arrangement avec soi, l'entourage et l'extérieur. Ainsi des chômeurs renoncent à chercher du travail pour se protéger contre les jugements négatifs de soi que renvoie une recherche de travail répétée et infructueuse ${ }^{17}$. D'une certaine façon, l'échange au guichet de l'ANPE relève lui aussi d'une négociation de l'identité entre le demandeur d'emploi et l'agent de l'institution.

Par ailleurs, l'engagement militant permet à certains chômeurs de retrouver une estime de soi. Dans ce cas, l'engagement est le support d'une reconstruction de l'individu, souvent associé à un rejet des classifications et des catégories pour revendiquer une situation dans la société selon son propre vécu ${ }^{18}$.

Ces « bricolages » autour de l'identité visent à alléger le fardeau du chômage véhiculé par les représentations dominantes, car si la disqualification sociale peut découler du chômage, l'existence d'identités négatives paraît plus problématique.

14- Didier Demazière, op. cit., 2003

15- Danièle Linhart, Perte d'emploi, perte de soi, Toulouse, Erès, 2002.

16- Dominique Meda, Le Travail, Paris, PUF, 2004 ; Evelyne Perrin, Chômeurs et précaires an cour de la question sociale, Paris, La Dispute, 2004.

17- Evelyne Perrin, op. cit.

18- Ibidem. 


\section{Les mobilisations de chômeurs mettent-elles en scène une identité collective?}

Il ne s'agit pas ici d'entreprendre une histoire des mobilisations de chômeurs, mais plutôt d'interroger le postulat selon lequel l'action collective n'existe pas sans la mobilisation d'une identité collective. C'est pourquoi nous nous pencherons, d'une part, sur les efforts des syndicats pour organiser les chômeurs et, d'autre part, sur la création depuis les années 1980 d'organisations de chômeurs autonomes.

\section{"Je, nous et les autres» à travers l'action collective des chômeurs}

Par action collective, la sociologie entend un agir-ensemble intentionnel, volontaire et concerté, recourant à des formes de protestation en vue de faire aboutir des revendications. Cela suppose la désignation d'un adversaire et la dénonciation d'une situation vécue comme injuste. La mobilisation collective implique un travail politique de construction et, ainsi, une capacité à entraîner et à faire tenir ensemble des chômeurs pour s'investir dans une cause, par-delà ce qui les différencie dans leurs vécus du chômage et leurs intérêts multiples. Ce travail est d'autant plus nécessaire que le groupe des chômeurs est marqué par une hétérogénéité et une instabilité fortes ${ }^{19}$. Le « nous » exprimé par l'action collective est donc construit. Il n'est pas simplement l'addition des individus engagés, mais l'expression d'un "agir-ensemble». Pour adhérer à une organisation ou à un mouvement, il faut accepter d'être reconnu par les autres comme membre de ce groupe. L'engagement individuel des chômeurs est donc lui aussi un élément à prendre en compte dans le processus de mobilisation, d'autant plus que les sans-emploi sont classiquement décrits comme dotés d'une identité individuelle négative. Les travaux de Sophie Maurer ${ }^{20}$, consacrés aux chômeurs engagés dans le mouvement de l'hiver 1997-1998, montrent bien comment l'engagement peut devenir le lieu d'un réinvestissement de soi et d'une réhabilitation du « je ».

19- Erik Neveu, Sociologie des mouvements sociaux, Paris, La Découverte, 2002. Sur les mobilisations de chômeurs : Sophie Maurer et Emmanuel Pierru, « Le mouvement des chômeurs de l'hiver 1997-1998. Retour sur un miracle social », Revue française de science politique, vol. 51, $\mathrm{n}^{\circ} 3$ (juin 2001), p. 371-407.

20- Sophie Maurer, Les Chômeurs en action (décembre 1997 - mars 1998). Mobilisation collective et ressources compensatoires, Paris, L'Harmattan, 2001. 
Le «nous » exprimé par les mouvements de chômeurs n'est pas pour autant celui d'une identité collective structurée. Il existe à travers l'action et la mobilisation ${ }^{21}$. Il est loin d'exprimer une " communauté de destins ». Parmi les «autres », il y a les salariés, que nombre de chômeurs aspirent à rejoindre. Revendiquer en tant que chômeur ou " privé d'emploi » peut être aussi bien un moyen d'exprimer son appartenance sociale au groupe des travailleurs.

\section{L'action syndicale en direction des chômeurs}

À partir de l'entre-deux-guerres naissent les premiers comités de chômeurs organisés par les syndicats. Durant la dépression des années 1930, les comités de la CGTU s'organisent et portent des revendications qui frappent par leur actualité. Le droit au travail, mais aussi le droit au revenu, le «salaire vital » ou encore la revendication des transports et des soins gratuits sont justifiés par l'insuffisance des secours de chômage et l'absence de droits pour les chômeurs ${ }^{22}$. La volonté des syndicats d'organiser les chômeurs traduit le souci de les maintenir dans le sein du mouvement ouvrier. Chômeurs et salariés doivent lutter ensemble, affirme la CGTU. L'enjeu est de taille pour les syndicats, dans la mesure où les phases de chômage s'accompagnent alors d'une dégradation des conditions de travail et de salaire, ainsi que d'un affaiblissement de l'action syndicale. La protestation est rendue plus difficile par la menace de la perte d'emploi. La CGTU souligne l'avantage que le chômage procure au patronat qui dispose d'une réserve de main-d'œuvre à laquelle il peut imposer des salaires dégradés. On peut également supposer que les comités de chômeurs permettent aux syndicats de poursuivre leur action militante, bien qu'ils soient en perte de vitesse, en tentant d'enrayer le recul de l'action collective et de conserver leurs adhérents ${ }^{23}$. En incluant les chômeurs dans le mouvement syndical, c'est-à-dire dans le mouvement ouvrier, l'appartenance des chômeurs à la classe ouvrière est mise en avant. L'unité de celle-ci, qui découle largement d'une construction idéologique plus que d'une réalité sociologique, est en jeu.

21- Ainsi les marches sont l'un des moyens d'action utilisés de manière récurrente lors des mobilisations de chômeurs. En 1933, la CGTU organisait une «marche de la faim ». Plus récemment, on peut évoquer la marche des chômeurs de 1994, puis la marche européenne de 1997. Voir le numéro spécial de la revue Mouvement social consacré aux "Marches », sous la direction de Michel Pigenet et Danielle Tartakowsky, $\mathbf{n}^{\circ} 202$ (janvier-mars 2003).

22- Isabelle Raynaud, mémoire cité.

23- Ibidem. 
Le droit au travail est, par ailleurs, une revendication commune des salariés et des chômeurs et, à partir de 1946, sa reconnaissance par le préambule de la Constitution fait officiellement du chômage une injustice que la société doit combattre ${ }^{24}$. À partir de 1958, la création de l'UNEDIC signifie la création d'un droit à l'indemnisation pour les chômeurs. Le chômage est alors faible et le revenu de remplacement élevé. La condition de chômage ne signifie pas une perte d'identité, dans le cas d'un chômage de courte durée et qui n'entraîne pas la pauvreté. Avec la crise brutale de 1973 et la montée du chômage, les comités de chômeurs se reconstituent. La CGT affirme, dès 1977-1978, sa volonté d'organiser les chômeurs dans un réseau de comités des " privés d'emploi ». Cette nouvelle terminologie traduit la désaffection pour le qualificatif de "chômeur », dont la connotation apparaît négative. Au contraire, " privé d'emploi » met en avant la revendication du travail et le caractère subi du chômage. Mais la mobilisation des chômeurs reste peu visible et la majorité parait silencieuse. Pourtant, à partir de 1989, un mouvement de chômeurs vigoureux se développe dans la région de Marseille. Déclenché par l'annonce de la fermeture des chantiers navals de La Ciotat, il est structuré par le comité CGT. À l'échelle locale, le mouvement s'inscrit dans la durée $e^{25}$. Il connait un certain retentissement, mais reste un cas isolé en France. En 1997-1998, la forte mobilisation dans les Bouches-du-Rhône ainsi que l'action conjointe des différentes organisations de chômeurs ont joué un rôle moteur, contribuant à expliquer un mouvement d'une ampleur nationale et d'une importance inédite ${ }^{26}$.

Si tous les syndicats ne se sont pas engagés dans la mobilisation des chômeurs, si certains y ont mieux réussi que d'autres, les exemples développés montrent que les organisations syndicales se considèrent comme représentatives des salariés, qu'ils aient ou non un emploi.

24- Christian Chevandier et Gilles Morin (dir.), André Philip, socialiste, patriote, chrétien, Paris, Comité pour l'histoire économique et financière de la France, 2005.

25- Marie-Laure Pouchadon, "La mobilisation collective des chômeurs », thèse de doctorat de sociologie, université de Bordeaux 2, 2002.

26- Pour une étude de cette mobilisation, on pourra également consulter : Didier Demazière et Maria-Teresa Pignoni, Chômeurs : du silence à la révolte. Sociologie d'une action collective, Paris, Hachette, 1998. 


\section{Les organisations autonomes de chômeurs}

Dans les années 1980 et 1990 apparaissent pour la première fois des organisations de chômeurs autonomes. En 1982, la création du syndicat des chômeurs marque un tournant. Maurice Pagat souhaite ainsi créer une organisation représentative des chômeurs ; il s'inscrit en opposition frontale avec les syndicats de salariés. Jusqu'en 1989, l'organisation développe diverses actions sans parvenir à atteindre l'objectif initial qu'elle s'était fixé. Les travaux d'Olivier Fillieule ${ }^{27}$ ont montré le poids des contraintes externes que constitue la structure des opportunités politiques dans cet échec. Ainsi, le traitement étatique du chômage peutil être un frein à la mobilisation des chômeurs. Devant les instances qui gèrent le chômage, la question politique disparait derrière les dossiers individuels. Le chômage lui-même est présenté comme un problème économique et non comme une question politique. Les conflits entre le syndicat des chômeurs et les confédérations syndicales ont empêché également son intégration au mouvement social.

Plus que l'adhésion au travail salarié et au groupe qu'il constitue, les organisations de chômeurs telles que l'APEIS ${ }^{28}$, le $\mathrm{MNCP}^{29}$ et $^{\mathrm{AC}} \mathrm{C}^{30}$ se revendiquent comme composantes du mouvement des « chômeurset-précaires ». Cette catégorie alternative est fondée sur une critique et un désaveu de la catégorie officielle du chômage, jugée trop floue, non pertinente, voire manipulée. Le chômage ne rendrait plus compte de la réalité sociale de manière pertinente ; les chiffres en seraient tronqués. La dégradation du rapport salarial, qui se traduit par une hausse des emplois précaires, rendrait plus pertinente la catégorie élargie des « chômeurs-et-précaires » dont les membres connaissent alternance de travail, de chômage ou encore de formation. Cette catégorie peut susciter un

28- L'Association pour l'emploi, l'information et la solidarité des chômeurs et travailleurs précaires, fondée en 1987, est surtout implantée dans le Val-de-Marne. Elle fut créée à l'initiative du parti communiste. Cette association s'organise selon une structure fédérative. Voir François Bourneau et Virginie Martin, «Organiser les sans emploi ? L'expérience de l'APEIS dans le Val-de-Marne ", in Olivier Fillieule (dir.), op. cit. 29- Le Mouvement national des chômeurs et précaires est né en 1986, dans le but de constituer une fédération des associations de chômeurs. Maurice Pagat en est le fondateur, mais il quitte l'organisation en 1992.

30- « Agir ensemble contre le chômage » est créé en 1994 sous la forme d'une association ouverte aux chômeurs et aux salariés. L'initiative est prise par des militants syndicaux issus du mouvement dit « autonome » et les organisations de chômeurs déjà existantes. 
sentiment d'appartenance, un processus d'identification ${ }^{31}$. Elle ne constitue ni un statut, ni un groupe homogène, mais un ensemble plus nombreux que celui des chômeurs.

Malgré les différences qui existent entre les organisations de chômeurs, toutes fonctionnent sur une base fédérative. Elles agissent à la fois sur un terrain social, en intervenant sur des dossiers individuels, de manière à permettre aux chômeurs de disposer de leurs droits, et sur un terrain politique, en mettant en cause le traitement du chômage et la politique de l'emploi.

Les mobilisations de chômeurs et, plus largement, des groupes dits «à faibles ressources » permettent de contester le postulat selon lequel toute mobilisation collective présuppose une identité collective forte. Elle suppose en revanche, en un moment donné, une finalité et un adversaire communs, ainsi que des agents capables de construire un agir-ensemble et de le rendre visible. L'absence d'identité collective peut cependant expliquer la fragilité et l'intermittence des mobilisations de chômeurs. Mais d'autres facteurs constituent un frein important. Ainsi, les secours revendiqués autrefois par les chômeurs mobilisés existent aujourd'hui. Le traitement du chômage, par son existence, pourrait ainsi décourager la mobilisation, alors même que les critiques et les revendications des organisations de chômeurs portent sur son fonctionnement et sur ses moyens.

Le concept d'identité, appliqué à la catégorie des chômeurs, apparait, in fine, comme plus ou moins opératoire. Comme nous l'avons montré, le chômage porte atteinte aux identités, tant individuelle que collective. Il n'est pas source d'identification, car il est une condition et non un état. Il ne relève pas de "l'être", mais pose la question de «l'avoir ». En ce sens, une étude du chômage à la lumière de la mobilité professionnelle et sociale pourrait enrichir la réflexion. Sans doute cette étude permet-elle de souligner une fois encore que les identités ne sont pas données et surtout pas figées, mais qu'elles découlent d'un processus de construction, subissent des évolutions et s'avèrent fluctuantes. Le chômage relève d'abord d'une catégorisation, mais ne crée pas un groupe social homogène et stable. La catégorie du chômage est elle

31- Voir sur ce point l'analyse de Patrick Cingolani, La République, les sociologues et la question politique, Paris, La Dispute / Snédit, 2003 (3 $3^{\mathrm{e}}$ partie : "Nouvelle question sociale, nouvelles subjectivations politiques ", chapitre 5 : «Le compte des chômeurs ", p. 141-160). 
même le fruit d'une représentation, qui ne colle pas toujours à la représentation que s'en font les chômeurs, ni à celles qui sont véhiculées par les mobilisations de chômeurs. Représentations du chômage, mais aussi du travail, dans une perspective comparative et évolutive, pourraient ainsi constituer un objet de recherche, permettant d'approfondir les travaux actuels sur le chômage. 